\title{
Kesiapan Guru Sekolah Menengah Atas/Kejuruan Katolik dalam Penyelenggaraan Pembelajaran Daring di Era Pandemi COVID-19
}

\author{
Magdalena, Oktavianey G. P. H. Meman, Rezkie Zulkarnain, Varetha Lisarani* \\ Pendidikan dan Pengajaran Agama Katolik, STAKat Negeri Pontianak, Indonesia \\ *betzyvarethalisarani@gmail.com
}

\begin{abstract}
Abstrak
Pandemi Coronavirus disease 2019 (COVID-19) yang terjadi di seluruh dunia akhirnya memaksa sekolah untuk menyelenggarakan pembelajaran daring. Penyelenggaraan yang mendadak memunculkan pertanyaan apakah guru sebagai pelaksana lapangan sudah siap untuk melaksanakan pembelajaran daring, mengingat pengukuran kesiapan baik faktor teknologi, inovasi, manusia, dan pengembangan diri perlu dilakukan agar dapat memperoleh manfaat yang sebenarnya dari penyelenggaraan sistem pembelajaran daring. Adapun tujuan penelitian ini adalah untuk mengetahui kesiapan guru dalam pelaksanaan pembelajaran daring yang dilaksanakan di masa pandemi COVID-19. Penelitian ini adalah mixed method yang dilakukan dengan penyebaran angket kepada para guru di SMA/SMK Katolik di Kota Pontianak dan Kabupaten Kubu Raya Kalimantan Barat melalui bantuan form daring lalu menganalisis data kuantitatif dengan pemberian skor pada hasil angket, kemudian dilakukan wawancara untuk mendapatkan informasi lebih mendalam. Berdasarkan data penelitian diperoleh hasil bahwa secara keseluruhan SMA dan SMK Katolik di Kota Pontianak dan Kabupaten Kubu Raya telah siap melaksanakan pembelajaran daring di masa pandemi COVID-19.
\end{abstract}

Kata kunci: kesiapan guru, sekolah menengah atas katolik, sekolah menengah kejuruan katolik, pembelajaran daring, COVID-19.

Dikirim: 30 Januari 2021

Direvisi: 15 Maret 2021

Diterima: 19 Mei 2021

\section{Identitas Artikel:}

Magdalena, M., Meman, O. G. P. H., Zulkarnain, R., \& Lisarani, V. (2021). Kesiapan Guru Sekolah Menengah Atas Katolik dalam Penyelenggaraan Pembelajaran Daring di Era Pandemi COVID-19. Jurnal Ilmu Pendidikan (JIP) STKIP Kusuma Negara, 13(1), 12-22.

\section{PENDAHULUAN}

Di masa Pandemi COVID-19 yang sedang dialami oleh Indonesia, Menteri Pendidikan dan Kebudayaan Republik Indonesia mengeluarkan Surat Edaran 36962/MPK.A/HK/2020 pada 17 Maret 2020 supaya seluruh kegiatan belajar mengajar baik di sekolah maupun di kampus perguruan tinggi melaksanakan pembelajaran secara daring sebagai upaya pencegahan terhadap perkembangan dan penyebaran Coronavirus Disease yang lebih dikenal dengan COVID-19 (Makarim, 2020). Pembelajaran daring merupakan bentuk penyampaian pembelajaran konvensional yang dituangkan pada format digital melalui internet sehingga memungkinkan aktivitas pengajaran dilaksanakan terpisah dari aktivitas belajar di mana gaya dan pola mengajar guru yang tadinya manual berubah menjadi digital (Imania, 2019; Sudarma, 2021; Uno, 2009). Pembelajaran daring dianggap sebagai alternatif terbaik penyampaian materi antara guru dan siswa pada masa pandemi, namun peralihan pembelajaran dari yang semula tatap muka menjadi pembelajaran daring memunculkan banyak hambatan bagi sekolah, guru, 
dan siswa, mengingat hal ini terjadi secara mendadak tanpa adanya persiapan sebelumnya (Noviansyah \& Mujiono, 2021). Masalah-masalah itu antara lain meliputi akses internet dan listrik yang terbatas, siswa kekurangan ruang sosialisasi, mudah terdistraksi, dan mudah stress, diperlukannya penyesuaian kurikulum, tenaga pendidik kesulitan beradaptasi dengan teknologi pembelajaran, guru kesulitan mengidentifikasi siswa yang tertinggal pelajaran, gadget milik siswa memiliki spesifikasi yang kurang mumpuni, kurangnya waktu berdiskusi antara guru dan siswa, dan masih banyak lagi (Hutauruk \& Sidabutar, 2020; Noviansyah \& Mujiono, 2021; Widyastuti, 2021).

Sistem pembelajaran daring menuntut kesiapan dari sisi infrastruktur serta kemampuan teknis dari calon penggunanya (Aydin \& Tasci, 2005). Namun berdasarkan hasil identifikasi lapangan awal peneliti kepada sejumlah guru di 6 SMA/SMK Katolik di Kota Pontianak dan Kabupaten Kubu Raya Provinsi Kalimantan Barat, guru dan siswa merasa belum siap dengan penyelenggaraan pembelajaran daring. Beberapa keluhan yang disampaikan antara lain: (1) belum siapnya guru menerima perubahan manajemen kegiatan pembelajaran dan perubahan metode pembelajaran, (2) tidak semua guru memiliki perangkat teknologi yang mendukung (3) kebutuhan biaya yang besar karena selalu menggunakan jaringan internet, (4) kesulitan mengoperasikan aplikasi pembelajaran yang terbaru khususnya oleh guru yang berusia lanjut, (5) guru kesulitan menjelaskan materi tanpa bertatap muka secara langsung dengan siswa, (6) guru kesulitan memvariasikan kelas supaya siswa tidak bosan dan bisa tetap fokus dalam mengikuti pembelajaran. Beberapa keluhan tersebut sangat berdampak pada efektifitas pembelajaran, sehingga perlu adanya observasi lebih lanjut agar dapat diketahui tingkat guru, dan siswa dalam penyelenggaraan pembelajaran daring serta dapat mengetahui hambatan-hambatan yang terjadi selama kegiatan tersebut.

Kesiapan adalah keseluruhan kondisi seseorang yang membuatnya siap untuk memberi respons/jawaban di dalam cara tertentu terhadap suatu situasi (Slameto, 2013). Pengukuran kesiapan perlu dilakukan agar dapat memperoleh manfaat yang sebenarnya dari penyelenggaraan sistem pembelajaran daring (Lopes, 2007). Dalam penerapannya pembelajaran daring membutuhkan kesiapan khususnya guru sebagai pelaksana pembelajaran daring. Kesiapan belajar perlu memperhatikan kesiapan fisik, psikis dan materiil (Suyati, 2019). Selain itu, terdapat pula beberapa persiapan yang perlu dilakukan dalam belajar agar terjadi kesiapan belajar, yaitu persiapan mental dan persiapan sarana. Faktor-faktor yang dapat menjadi tolak ukur kesiapan penyelenggaraan daring yaitu: (1) faktor teknologi (2) faktor inovasi (3) faktor manusia, dan (4) faktor pengembangan diri (Kong dkk., 2014).

Proses adopsi pembelajaran daring untuk suatu organisasi harus dilaksanakan secara hati-hati untuk mengurangi resiko cost overruns, produk pembelajaran yang tidak menarik, serta kegagalan (Chapnick, 2000). Dengan demikian penelitian tentang kesiapan guru dalam penerapan pembelajaran daring perlu dilakukan sehingga hasil penelitian dapat menjadi bahan pertimbangan bagi guru dalam usaha penyempurnaan kegiatan pembelajaran daring, mengingat pandemi COVID-19 ini masih belum berakhir. Oleh karena itu dilakukan penelitian dengan judul "Kesiapan Guru Sekolah Menengah Atas/Kejuruan Katolik dalam Penyelenggaraan Pembelajaran Daring di Era Pandemi COVID-19" untuk 
mengetahui bagaimana tingkat kesiapan guru dalam pelaksanaan pengajaran daring khususnya di Kota Pontianak dan Kabupaten Kubu Raya Kalimantan Barat.

\section{METODE PENELITIAN}

Penelitian ini merupakan penelitian mixed method yaitu metode penelitian dengan mengkombinasikan antara dua metode penelitian sekaligus, kualitatif dan kuantitatif dalam suatu kegiatan penelitian, sehingga akan diperoleh data yang lebih komprehensif, valid, reliabel, dan objektif (Sugiyono, 2010). Penelitian ini menggunakan teknik campuran bertahap di mana peneliti menggabungkan data yang ditemukan dari satu metode dengan metode lainnya (Creswell, 2002). Penelitian ini menggunakan mode embeded di mana penelitian kualitatif menghasilkan tujuan penelitian yang sama dengan penelitian kuantitatif. Dengan demikian dilakukan pengumpulan dan analisis data follow-up kualitatif untuk menerangkan hasil kuantitatif (Creswell, 2017).

Tahap pertama dilakukan dengan penyebaran angket kepada para guru melalui bantuan form daring lalu menganalisis data kuantitatif dengan pemberian skor pada hasil angket, kemudian dilakukan wawancara sejumlah guru untuk mendapatkan informasi lebih mendalam khususnya mengenai persiapan, kendala, dan pandangan guru mengenai pelaksanaan pembelajaran daring yang sudah berjalan.

Subjek penelitian dalam penelitian ini adalah guru pengajar di SMA/SMK Katolik di Kota Pontianak dan Kabupaten Kubu Raya Kalimantan Barat yaitu SMA Gembala Baik, SMA St. Paulus, SMA St. Petrus, SMK St. Maria, SMA St. Fransiskus Asisi, dan SMK Santa Monika. Keenam sekolah tersebut seluruhnya melaksanakan pembelajaran daring selama masa pandemi COVID-19.

Instrumen pengumpul data dalam penelitian ini adalah angket dan pedoman wawancara semi terstruktur untuk mengetahui tingkat kesiapan guru terkait penyelenggaraan pembelajaran daring di masa pandemi COVID-19 khususnya dalam faktor teknologi, inovasi, manusia, dan pengembangan diri. Data yang diperoleh kemudian diolah secara kuantitatif dan kualitatif. Angket penelitian ini memiliki 20 pertanyaan untuk guru dengan alternatif jawaban "Sangat setuju" dengan skor 4, "Setuju" dengan skor 3, "Tidak Setuju" dengan skor 2, dan "Sangat Tidak Setuju" dengan skor 1. Setelah lembar penilaian diisi oleh responden akan diperoleh skor total, selanjutnya dihitung rata-rata akhir dengan menggunakan rumus berikut.

$$
\bar{x}=\frac{\sum \mathrm{x}}{n}
$$

Keterangan: $\bar{x}=$ rata-rata akhir; $\sum x=$ jumlah skor total; dan $n=$ jumlah responden.

Skor rata-rata pertanyaan untuk satu faktor yang sama dan skor rata-rata total dari semua pertanyaan akan dinilai menggunakan skala penilaian e-Learning Readiness Survey (e-LRS) oleh Aydin \& Tasci (2005). Berdasarkan hasil pengolahan data yang diperoleh dari angket, ditentukan status level kesiapan guru melaksanakan pembelajaran daring berdasarkan modifikasi model Aydin \& Tasci yang dapat dilihat pada Tabel 1. 
15 | Magdalena, Meman, Zulkarnain \& Lisarani, Kesiapan Guru Sekolah Menengah ...

Tabel 1. Status level kesiapan guru melaksanakan pembelajaran daring modifikasi model Aydin \& Tasci (2005)

\begin{tabular}{ccl}
\hline Level & Skor Kesiapan & \multicolumn{1}{c}{ Status } \\
\hline Level 1 & $1-1.75$ & Tidak siap, membutuhkan banyak peningkatan \\
Level 2 & $1.76-2.5$ & Tidak siap, membutuhkan sedikit peningkatan \\
Level 3 & $2.51-3.25$ & Siap, membutuhkan sedikit peningkatan \\
Level 4 & $3.26-4$ & Siap,bisa dilanjutkan \\
\hline
\end{tabular}

Faktor dan konstruk yang digunakan untuk mengidentifikasi kesiapan sekolah bisa dilihat pada Tabel 2 .

Tabel 2. Faktor dan konstruk yang digunakan untuk mengidentifikasi kesiapan sekolah modifikasi model Aydin \& Tasci (2005)

\begin{tabular}{llll}
\hline & Sumber & Keahlian & Sikap \\
\hline Teknologi & $\begin{array}{l}\text { Akses kepada } \\
\text { komputer dan } \\
\text { internet }\end{array}$ & $\begin{array}{l}\text { Kemampuan } \\
\text { menggunakan } \\
\text { komputer dan } \\
\text { internet }\end{array}$ & $\begin{array}{l}\text { Sikap positif } \\
\text { kepada penggunaan } \\
\text { teknologi }\end{array}$ \\
\hline Inovasi & Hambatan & $\begin{array}{l}\text { Kemampuan } \\
\text { mengadaptasi } \\
\text { inovasi }\end{array}$ & $\begin{array}{l}\text { Keterbukaan } \\
\text { terhadap inovasi }\end{array}$ \\
\hline Manusia & $\begin{array}{l}\text { Pendidikan, } \\
\text { pengalaman guru, } \\
\text { pihak eksternal }\end{array}$ & $\begin{array}{l}\text { Kemampuan belajar } \\
\text { menggunakan } \\
\text { teknologi }\end{array}$ & \\
\hline $\begin{array}{l}\text { Pengembangan } \\
\text { diri }\end{array}$ & Budget & $\begin{array}{l}\text { Kemampuan } \\
\text { memanajemen } \\
\text { waktu }\end{array}$ & $\begin{array}{l}\text { Kepercayaan } \\
\text { terhadap } \\
\text { pengembangan diri }\end{array}$ \\
\hline
\end{tabular}

\section{HASIL DAN PEMBAHASAN}

Angket yang disebarkan kepada guru di 6 SMA/SMK Katolik di Kota Pontianak dan Kabupaten Kubu Raya Kalimantan Barat diisi oleh 102 responden dengan rincian yang dapat dilihat pada Tabel 3.

Tabel 3. Rekapitulasi responden angket di SMA/SMK Katolik Kota Pontianak dan Kabupaten Kubu Raya Kalimantan Barat

\begin{tabular}{clc}
\hline No. & \multicolumn{1}{c}{ Sekolah } & Banyak Responden \\
\hline 1 & SMA Gembala Baik & 11 orang \\
2 & SMA St. Paulus & 34 orang \\
3 & SMA St. Petrus & 29 orang \\
4 & SMK St. Maria & 7 orang \\
5 & SMA St. Fransiskus Asisi & 10 orang \\
6 & SMK Santa Monika & 11 orang \\
\hline & \multicolumn{1}{c}{ Total } & 102 orang \\
\hline
\end{tabular}

Berdasarkan data yang telah dihimpun dari guru di 6 SMA/SMK Katolik di Kota Pontianak dan Kabupaten Kubu Raya, setiap sekolah termasuk dalam 
kategori telah siap melaksanakan pembelajaran daring di masa pandemi COVID19. Selain itu, secara keseluruhan diperoleh jumlah skor 7395 dan skor rata-rata 3,59 dalam penilaian kesiapan guru sehingga bisa disimpulkan bahwa guru di ketujuh sekolah ini sudah berada pada level siap melaksanakan pembelajaran daring di masa pandemi COVID-19.

Tabel 4. Rekapitulasi hasil kesiapan guru dalam penyelenggaraan pembelajaran daring di masa pandemi COVID-19 di Kota Pontianak dan Kabupaten Kubu Raya Kalimantan Barat

\begin{tabular}{lccl}
\hline \multicolumn{1}{c}{ Sekolah } & $\begin{array}{c}\text { Jumlah } \\
\text { Skor }\left(\sum \mathrm{x}\right)\end{array}$ & $\begin{array}{c}\text { Skor Rata- } \\
\text { rata }(\bar{x})\end{array}$ & Kategori Kesiapan \\
\hline SMA Gembala Baik & 770 & 3.53 & Siap, bisa dilanjutkan \\
SMA St. Paulus & 2417 & 3.57 & Siap, bisa dilanjutkan \\
SMA St. Petrus & 2207 & 3.81 & Siap, bisa dilanjutkan \\
SMK St. Maria & 506 & 3.62 & Siap, bisa dilanjutkan \\
SMA St. Fransiskus Asisi & 752 & 3.65 & Siap, bisa dilanjutkan \\
SMK Santa Monika & 743 & 3.37 & Siap, bisa dilanjutkan \\
\hline Total & 7395 & 3.59 & Siap, bisa dilanjutkan \\
\hline
\end{tabular}

Pada sub bagian berikut akan dipaparkan mengenai hasil wawancara semi terstruktur mengenai persiapan, kendala, dan pandangan guru pengajar di masingmasing sekolah yang menjadi lokasi penelitian.

\section{SMA Gembala Baik}

Dengan dilaksanakannya pembelajaran daring, materi yang selama ini dikemas dalam bentuk cetak harus diubah dalam bentuk digital. Untuk memfasilitasi hal tersebut, sekolah menyelenggarakan pelatihan pembelajaran daring supaya guru semakin terbiasa dan seiring perjalanan waktu makin siap melaksanakan pembelajaran daring. Sekolah juga menerapkan kurikulum khusus di mana materi disederhanakan dan jam pembelajaran dikurangi. Meski demikian, berdasarkan wawancara dengan guru, siswa masih kesulitan memahami materi yang disampaikan dan guru mengatasinya dengan memberikan modul tambahan.

Tabel 5. Rekapitulasi hasil kesiapan guru SMA Gembala Baik dalam Penyelenggaraan Pengajaran Daring

\begin{tabular}{|c|c|c|c|}
\hline Faktor Kesiapan & $\begin{array}{l}\text { Jumlah Skor } \\
\left(\sum \mathrm{x}\right)\end{array}$ & $\begin{array}{l}\text { Skor Rata- } \\
\operatorname{rata}(\bar{x})\end{array}$ & Kategori Kesiapan \\
\hline Faktor Teknologi & 123 & 3.73 & Siap, bisa dilanjutkan \\
\hline Faktor Inovasi & 237 & 3.59 & Siap, bisa dilanjutkan \\
\hline Faktor Manusia & 201 & 3.65 & Siap, bisa dilanjutkan \\
\hline $\begin{array}{l}\text { Faktor } \\
\text { Pengembangan Diri }\end{array}$ & 209 & 3.17 & $\begin{array}{l}\text { Siap, membutuhkan sedikit } \\
\text { peningkatan }\end{array}$ \\
\hline Total & 770 & 3.53 & Siap, bisa dilanjutkan \\
\hline
\end{tabular}

Kendala yang dihadapi guru antara lain sulitnya mengidentifikasi pemahaman siswa terkait materi yang disampaikan. Guru juga merasa merasa harus terus menerus berinovasi supaya pembelajaran tidak dirasa jenuh karena interaksi guru dan siswa yang terbatas selama penerapan pembelajaran daring. 
Menurut guru yang kami wawancarai di SMA Gembala Baik, siswa masih memerlukan bimbingan dari guru karena tingkat kemandirian dan kesadaran belajar mereka masih perlu ditingkatkan. Guru juga memerlukan interaksi langsung untuk membentuk karakter dan tingkah laku positif siswa, karena tugas guru tidak hanya memberikan materi namun juga membentuk karakter siswa.

\section{SMA Santo Paulus}

Di SMA Santo Paulus, guru tetap membuat RPP sebagai pedoman pelaksanaan pembelajaran. Di masa awal lockdown (Maret/April 2020) guru belum memberikan materi. Di bulan Mei guru menggunakan email, groupchat, dan Learning Management System (LMS) untuk memfasilitasi pembelajaran daring. Dalam proses pelaksanaan pembelajaran daring, guru dituntut belajar dan meningkatkan kreativitas dalam menggunakan berbagai aplikasi guna mendukung pembelajaran daring. Sekolah melaksanakan suatu program pelatihan tidak terstruktur di mana guru-guru muda yang lebih memahami teknologi memberikan semacam pelatihan kepada guru-guru yang kurang mahir. Sekolah juga mengadakan webinar pembuatan materi pembelajaran online.

Tabel 6. Rekapitulasi hasil kesiapan guru SMA St. Paulus dalam Penyelenggaraan Pengajaran Daring

\begin{tabular}{lccc}
\hline \multicolumn{1}{c}{ Faktor Kesiapan } & $\begin{array}{c}\text { Jumlah Skor } \\
\left(\sum \mathrm{x}\right)\end{array}$ & $\begin{array}{c}\text { Skor Rata-rata } \\
(\bar{x})\end{array}$ & $\begin{array}{c}\text { Kategori } \\
\text { Kesiapan }\end{array}$ \\
\hline Faktor Teknologi & 371 & 3.64 & Siap, bisa dilanjutkan \\
Faktor Inovasi & 738 & 3.62 & Siap, bisa dilanjutkan \\
Faktor Manusia & 627 & 3.69 & Siap, bisa dilanjutkan \\
Faktor Pengembangan Diri & 681 & 3.34 & Siap, bisa dilanjutkan \\
\hline \multicolumn{1}{c}{ Total } & 2417 & 3.57 & Siap, bisa dilanjutkan \\
\hline
\end{tabular}

Sebelum tahun ajaran baru 2020/2021, sekolah mengadakan pertemuan pembuatan perangkat pembelajaran yang terfokus pada pembelajaran daring di mana materi disederhanakan dan disesuaikan sehingga hanya poin-poin penting yang disampaikan. Selain itu siswa juga diberi buku pegangan untuk membantu mereka memahami materi. Sekolah member sarana prasarana yang cukup untuk mendukung proses pembelajaran daring, antara lain menyiapkan komputer dan peningkatan kualitas wifi di sekolah.

Kendala yang dialami guru antara lain guru tidak bisa memastikan apakah siswa benar-benar memperhatikan pejelasan guru karena saat berlangsung pembelajaran daring dengan media video conference, siswa diminta mematikan kamera untuk meringankan kuota internet yang digunakan. Siswa juga sering tidak bisa mengikuti pembelajaran daring baik sebagian maupun seluruhnya karena masalah jaringan.

Bagi guru yang kami wawancarai di SMA Santo Paulus, pembelajaran tatap muka masih lebih efektif, karena interaksi guru-siswa dan siswa-siswa terbatas. Lebih lagi siswa dapat dengan mudah dibentuk budi pekertinya saat tatap muka, dan hal ini sulit dilaksanakan dalam pembelajaran daring. Hal ini disebabkan karena pada hakikatnya tugas guru bukanlah hanya mentransfer pengetahuan saja, melainkan juga membentuk karakter siswa. 


\section{SMA Santo Petrus}

Sebelum dihantam pandemi, Kepala SMA St. Petrus sudah merencanakan pembelajaran daring supaya siswa tidak perlu membawa buku yang banyak dan juga merupakan usaha mengurangi penggunaan kertas dalam kampanye go green. Beberapa guru juga sudah menggunakan aplikasi daring sebagai pelengkap dalam proses pembelajaran. Setelah masa pembelajaran daring dimulai, sekolah mengadakan pelatihan tentang penggunaan aplikasi pembelajaran daring, memberikan fasilitas wifi dan komputer, serta memberikan subsidi kepada siswa dan guru berupa pulsa untuk menunjang pembelajaran daring ini. Proses supervisi rutin juga tetap dilaksanakan untuk melihat persiapan guru dan proses pembelajaran. Supervisi yang biasanya dilakukan dengan mengunjungi langsung guru di kelas saat ini diubah dengan mengunjungi kelas daring yang diselenggarakan guru dalam video conference. Materi yang disampaikan disederhanakan dengan memilih materi esensial. Materi yang tidak terpilih tetap diberikan untuk dipelajari sendiri oleh siswa.

Tabel 7. Rekapitulasi hasil kesiapan guru SMA St. Petrus dalam Penyelenggaraan Pengajaran Daring

\begin{tabular}{lccc}
\hline \multicolumn{1}{c}{ Faktor Kesiapan } & $\begin{array}{c}\text { Jumlah Skor } \\
\left(\sum \mathrm{x}\right)\end{array}$ & $\begin{array}{c}\text { Skor Rata- } \\
\text { rata }(\bar{x})\end{array}$ & Kategori Kesiapan \\
\hline Faktor Teknologi & 333 & 3.83 & Siap, bisa dilanjutkan \\
Faktor Inovasi & 654 & 3.76 & Siap, bisa dilanjutkan \\
Faktor Manusia & 563 & 3.88 & Siap, bisa dilanjutkan \\
Faktor Pengembangan Diri & 657 & 3.78 & Siap, bisa dilanjutkan \\
\hline \multicolumn{1}{c}{ Total } & 2207 & 3.81 & Siap, bisa dilanjutkan \\
\hline
\end{tabular}

Kendala yang dialami selama proses pembelajaran daring di masa pandemiini adalah penguasaan guru terhadap aplikasi pembelajaran. Guru juga mengalami kesulitan membentuk karakter siswa. Secara ilmu pengetahuan siswa masih bisa mempelajari secara daring, namun mereka memerlukan bimbingan langsung untuk dapat dibina dan dibimbing. Solusi yang dapat diberikan guru dalam kondisi terbatas ini adalah dengan mengucapkan selamat pagi/siang, mengucapkan terima kasih, dan memulai pembelajaran dengan doa.

Bagi guru SMA St. Petrus, sekolah yang gurunya sudah menguasai teknologi tidak akan kesulitan menyelenggarakan pembelajaran daring dan justru merasa bahwa pembelajaran daring memudahkan proses belajar karena dapat dilakukan dimanapun dan kapanpun. Sedangkan di sisi lain, pembelajaran daring kurang efektif dalam pembentukan karakter siswa karena guru tidak bisa bertatap muka secara langsung dengan siswa.

\section{SMK Santa Maria}

SMK Santa Maria adalah satu-satunya SMK Katolik di Kota Pontianak Kalimantan Barat yang menjadi lokasi penelitian ini. Di masa pandemi, guru di SMK St. Maria membuat RPP 1 lembar sesuai dengan arahan Menteri Pendidikan Republik Indonesia. Sekolah memberikan fasilitas berupa laptop/komputer dan peningkatan kekuatan jaringan wifi. Selain itu, sekolah juga mengadakan pelatihan untuk mengembangkan kemampuan guru dalam mengelola pembelajaran daring. Dalam masa pandemi guru dituntut untuk lebih kreatif, 
sehingga guru bisa membuat beragam bentuk penyajian materi (slideshow, video, dan sebagainya) untuk membantu siswa memahami materi lebih mudah.

Tabel 8. Rekapitulasi hasil kesiapan guru SMK St. Maria dalam Penyelenggaraan Pengajaran Daring

\begin{tabular}{lccc}
\hline \multicolumn{1}{c}{ Faktor Kesiapan } & $\begin{array}{c}\text { Jumlah Skor } \\
\left(\sum \mathrm{x}\right)\end{array}$ & $\begin{array}{c}\text { Skor Rata-rata } \\
(\bar{x})\end{array}$ & Kategori Kesiapan \\
\hline Faktor Teknologi & 76 & 3.62 & Siap, bisa dilanjutkan \\
Faktor Inovasi & 149 & 3.55 & Siap, bisa dilanjutkan \\
Faktor Manusia & 131 & 3.74 & Siap, bisa dilanjutkan \\
Faktor Pengembangan Diri & 150 & 3.57 & Siap, bisa dilanjutkan \\
\hline \multicolumn{1}{c}{ Total } & 506 & 3.62 & Siap, bisa dilanjutkan \\
\hline
\end{tabular}

Kendala yang dialami guru yaitu siswa yang kurang cepat memahami materi dibanding saat pembelajaran luring. Guru juga kesulitan membentuk karakter siswa karena interaksi tatap muka sangat dibutuhkan untuk hal ini.

Pembelajaran daring bukanlah hal yang baru karena sebelum pandemi sudah diadakan di SMK St. Maria. Hanya saja, dengan adanya pandemi COVID-19, pembelajaran 'dipaksakan' untuk dilaksanakan. Menurut guru SMK St. Maria yang kami wawancarai, setelah pandemi sebaiknya pembelajaran daring tidak perlu dihilangkan, melainkan dikombinasikan dengan pembelajaran luring untuk memperkaya proses pembelajaran. Meski demikian, pembelajaran tatap muka memang lebih efektif dari pada pembelajaran daring karena guru bisa mendidik dan membentuk karakter, perilaku, tata krama, dan sopan santun siswa.

\section{SMA Santo Fransiskus Asisi}

Di masa awal pandemi, guru dan stakeholders SMA St. Fransiskus Asisi mengadakan pertemuan untuk membahas bagaimana strategi menghadapi pembelajaran daring, utamanya mengenai sarana dan prasarana yang bisa menunjang.Sekolah akhirnya memutuskan untuk memberikan fasilitas laptop meskipun jumlahnya terbatas dan meningkatkan kekuatan wifi. Selanjutnya diadakan pelatihan oleh guru yang lebih menguasai aplikasi-aplikasi pembelajaran daring kepada rekan guru yang lain. Materi pembelajaran dipilih yang esensial untuk diberikan kepada siswa, utamanya materi-materi yang penting untuk pergumulan hidup siswa.

Tabel 9. Rekapitulasi hasil kesiapan guru SMA St. Fransiskus Asisi dalam Penyelenggaraan Pengajaran Daring

\begin{tabular}{lccc}
\hline \multicolumn{1}{c}{ Faktor Kesiapan } & $\begin{array}{c}\text { Jumlah } \\
\text { Skor }\left(\sum \mathrm{x}\right)\end{array}$ & $\begin{array}{c}\text { Skor Rata- } \\
\text { rata }(\bar{x})\end{array}$ & Kategori Kesiapan \\
\hline Faktor Teknologi & 113 & 3.77 & Siap, bisa dilanjutkan \\
Faktor Inovasi & 211 & 3.52 & Siap, bisa dilanjutkan \\
Faktor Manusia & 194 & 3.88 & $\begin{array}{l}\text { Siap, bisa dilanjutkan } \\
\text { Faktor Pengembangan Diri }\end{array}$ \\
\multicolumn{1}{c}{ Total } & 207 & 3.45 & Siap, bisa dilanjutkan \\
\hline \multicolumn{1}{c}{ T25 } & 3.65 & $\begin{array}{c}\text { Siap, penerapan } e \text {-learning } \\
\text { dapat dilanjutkan }\end{array}$ \\
\hline
\end{tabular}


Kendala yang dihadapi guru antara lain karena siswa yang berada di daerah tidak memiliki perangkat yang menunjang untuk pembelajaran daring. Guru juga kesulitan membentuk karakter, sikap, dan tingkah laku siswa.

Menurut guru yang kami wawancarai di SMA St. Fransiskus Asisi, dalam pembelajaran daring materi masih bisa tersampaikan walaupun kurang maksimal. Meski demikian, pembelajaran daring kurang efektif karena pengajaran budi pekerti sulit dilakukan, padahal tugas guru tidak hanya mengajar materi saja.

\section{SMK Santa Monika}

SMK Santa Monika adalah satu-satunya SMK Katolik di Kabupaten Kubu Raya Kalimantan Barat yang menjadi lokasi penelitian ini. Pada penyelenggaraan pembelajaran daring, RPP tetap disiapkan untuk memperlancar jalannya pembelajaran. Pembelajaran dilaksanakan dengan bantuan aplikasi video conference dan siswa juga menggunakan buku pegangan. Sekolah memberikan fasilitas wifi dan bantuan dana kuota data khususnya pada saat Penilaian Tengah Semester (PTS) dan Penilaian Akhir Semester (PAS).

Tabel 10. Rekapitulasi hasil kesiapan guru SMA St. Monika dalam Penyelenggaraan Pengajaran Daring

\begin{tabular}{lccl}
\hline \multicolumn{1}{c}{ Faktor Kesiapan } & $\begin{array}{c}\text { Jumlah Skor } \\
\left(\sum \mathrm{x}\right)\end{array}$ & $\begin{array}{c}\text { Skor Rata- } \\
\text { rata }(\bar{x})\end{array}$ & \multicolumn{1}{c}{ Kategori Kesiapan } \\
\hline Faktor Teknologi & 109 & 3.30 & Siap, bisa dilanjutkan \\
Faktor Inovasi & 227 & 3.44 & Siap, bisa dilanjutkan \\
Faktor Manusia & 193 & 3.51 & Siap, bisa dilanjutkan \\
Faktor & 214 & 3.24 & $\begin{array}{l}\text { Siap, membutuhkan sedikit } \\
\text { Pengembangan Diri }\end{array}$ \\
\multicolumn{1}{c}{ Total } & 743 & 3.37 & Siap, bisa dilanjutkan \\
\hline
\end{tabular}

Berdasarkan hasil wawancara dengan guru SMK Santa Monika, tidak ada kendala yang berarti selama proses pembelajaran daring yang sudah berjalan. Hanya saja karena koneksi internet sangat diperlukan dalam pra, proses, maupun pasca pembelajaran daring, maka dari segi finansial terdapat pengeluaran tambahan untuk membeli kuota data meskipun sudah ada bantuan dari instansi,

Menurut guru yang kami wawancarai, pembelajaran tatap muka lebih maksimal karena semua materi dapat disampaikan dengan baik. Meski demikian, pembelajaran daring yang sudah berjalan cukup efektif, karena materi dipersiapkan dengan baik dan siswa juga bisa memahami karena pembelajaran dilengkapi dengan buku pegangan siswa. Hal yang perlu diperhatikan adalah dalam pembelajaran daring guru mengalami keterbatasan dalam membimbing karakter/tingkah laku siswa, padahal tugas guru bukanlah hanya mengajar, namun juga mendidik siswa.

\section{SIMPULAN}

Berdasarkan hasil analisis data yang diperoleh, dapat disimpulkan bahwa secara keseluruhan SMA dan SMK Katolik di Kota Pontianak dan Kabupaten Kubu Raya telah siap melaksanakan pembelajaran daring di masa pandemi COVID-19 dengan skor rata-rata 3,59. Secara umum di awal masa pandemi guru merasa 
kesulitan karena secara mendadak harus melaksanakan pembelajaran daring, namun seiring dengan berjalannya waktu guru mampu menyesuaikan. Bantuan yang diberikan sekolah antara lain peningkatan kualitas wifi, komputer/laptop bagi guru yang membutuhkan, kuota data/pulsa untuk menunjang kebutuhan guru, serta workshop/pelatihan terkait pembelajaran daring. Kendala yang dialami guru antara lain adanya tambahan pengeluaran finansial, kesulitan guru mengoperasikan aplikasi penunjang pembelajaran daring, beberapa siswa kesulitan mengikuti pembelajaran daring karena berbagai keterbatasan, guru kesulitan mengidentifikasi apakah siswa sudah memahami materi, kejenuhan dalam proses pembelajaran, serta kesulitan dalam membentuk budi dan karakter siswa karena terbatasnya interaksi antara guru dan siswa. Pembelajaran daring yang sudah terlaksana selama masa pandemi ini dengan segala kendala dan kekurangannya belum bisa dengan maksimal memfasilitasi tugas guru untuk tidak hanya mengajar materi namun juga mendidik siswa dalam hal karakter, tingkah laku, sopan santun, dan budi pekerti.

\section{UCAPAN TERIMA KASIH}

Terima kasih kepada Sekolah Tinggi Agama Katolik Negeri Pontianak sebagai pemberi dana penelitian dari DIPA tahun anggaran 2020 berdasar Keputusan Ketua Sekolah Tinggi Agama Katolik Negeri Pontianak no. 19 tahun 2020.

\section{REFERENSI}

Aydin, C., \& Tasci, D. (2005). Measuring Readiness for e-Learning: Reflections from an Emerging Country. Educational Technology \& Society, 8, 244-257.

Chapnick, S. (2000). Are You Ready for E-Learning? Learning Circuits: ATSD's Online Magazine All About ELearning [HTML File]. Tersedia: http://www.astd.org/LC/2000/1100_chapnick.htm

Creswell, J. W. (2002). Educational Research: Planning, Conducting, and Evaluating Quantitative and Qualitative Research. New Jersey: Pearson Education, Inc.

Creswell, J. W. (2017). Research Design Pendekatan Metode Kualitatif, Kuantitatif, dan Campuran. Yogyakarta: Pustaka Pelajar.

Hutauruk, A., \& Sidabutar, R. (2020). Kendala Pembelajaran Daring Selama Masa Pandemi di Kalangan Mahasiswa Pendidikan Matematika: Kajian Kualiatatif Deskriptif. SEPREN: Journal of Mathematics Education and Applied, 02(01), 45-51. https://doi.org/10.36655/sepren.v2i1.364

Imania, K. A. N. (2019). Rancangan Pengembangan Instrumen Penilaian Pembelajaran Berbasis Daring. Jurnal PETIK, 5, 31-47. https://doi.org/10.31980/jpetik.v5i1.445

Kong, S., Chan, T.-W., Griffin, P., Hoppe, U., Huang, R., Kinshuk, D., Looi, C.K., Milrad, M., Norris, C., Nussbaum, M., Sharples, M., So, W., Soloway, E., \& Yu, S. (2014). E-learning in School Education in the Coming 10 Years for Developing 21st Century Skills: Critical Research Issues and Policy Implications. Educational Technology \& Society, Volume 17(1), 70-78.

Lopes, C. T. (2007). Evaluating e-learning readiness in a health sciences higher education institution. IADIS International Conference ELearning, pp. 59-67. 
Noviansyah, W., \& Mujiono, C. (2021). Analisis Kesiapan dan Hambatan Siswa SMK dalam Menghadapi Pembelajaran Daring di Masa Pandemi. Jurnal Studi $\begin{array}{llll}\text { Guru dan } & \text { Pembelajaran, }\end{array}$ https://doi.org/10.30605/jsgp.4.1.2018.522

Makarim, N. A. (2020). Surat Edaran Mendikbud: Pembelajaran secara Daring dan Bekerja dari Rumah untuk Mencegah Penyebaran COVID-19. Kementerian Pendidikan dan Kebudayaan [HTML File]. Tersedia: https://www.kemdikbud.go.id/main/blog/2020/03/se-mendikbudpembelajaran-secara-daring-dan-bekerja-dari-rumah-untuk-mencegahpenyebaran-covid19

Slameto. (2013). Belajar dan Faktor-faktor yang Mempengaruhinya. Jakarta: Rineka Cipta.

Sudarma, M. (2021). Daring Duraring Belajar dari Rumah: Strategi Jitu Guru, Orang Tua, dan Siswa di Masa Pandemi. Jakarta: PT Elex Media Komputindo.

Sugiyono. (2010). Metode Penelitian Kombinasi (Mixed Methods). Bandung: Alfabeta.

Suyati. (2019). Meningkatkan Peranan Guru Profesional Dalam Menghadapi Era Revolusi Industri 4.0. Prosiding Seminar Nasional Pendidikan Program Pascasarjana Universitas PGRI Palembang, pp. 957-963.

Uno, H. B. (2009). Model Pembelajaran Menciptakan Proses Belajar Mengajar yang Kreatif dan Efektif. Jakarta: Bumi Aksara.

Widyastuti, A. (2021). Optimalisasi Pembelajaran Jarak Jauh (PJJ), Daring Luring, BDR. Jakarta: PT Elex Media Komputindo. 